\title{
Balkanologie
}

Balkanologie Revue d'études pluridisciplinaires

Vol. IX, n' 1-2 | 2005

Volume IX Numéro 1-2

\section{Ethnologie française, (2), 2005, « Grèce-Ellada. Figures de l'altérité »}

\section{Gilles de Rapper}

\section{(2) OpenEdition}

1 Journals

\section{Édition électronique}

URL : http://journals.openedition.org/balkanologie/2031

DOI : 10.4000/balkanologie.2031

ISSN : 1965-0582

Éditeur

Association française d'études sur les Balkans (Afebalk)

Édition imprimée

Date de publication : 1 décembre 2005

ISSN : 1279-7952

\section{Référence électronique}

Gilles de Rapper, «Ethnologie française, (2), 2005, «Grèce-Ellada. Figures de l'altérité » », Balkanologie [En ligne], Vol. IX, n 1-2 | 2005, mis en ligne le 14 janvier 2010, consulté le 17 décembre 2020. URL: http://journals.openedition.org/balkanologie/2031; DOI : https://doi.org/10.4000/balkanologie.2031

Ce document a été généré automatiquement le 17 décembre 2020.

(ㄷ) Tous droits réservés 


\title{
Ethnologie française, (2), 2005, "Grèce-Ellada. Figures de l'altérité »
}

\author{
Gilles de Rapper
}

\section{RÉFÉRENCE}

Ethnologie française, (2), 2005, « Grèce-Ellada. Figures de l'altérité ». 371 p.

1 Reprenant le modèle naguère appliqué à la Roumanie $\left(n^{\circ} 3,1995\right)$ et à la Bulgarie $\left(n^{\circ} 2\right.$, 2001), la revue Ethnologie française consacre un numéro spécial à la Grèce : il s'agit de donner la parole à des anthropologues grecs travaillant sur leur propre société, afin de fournir un état des lieux de la discipline et des questions qui lui sont posées par la société grecque des années 1990. Dans sa contribution («Un moment pluriel. L'ethnographie grecque au tournant du siècle») Evthymios Papataxiarchis, coordinateur (avec Jean Cuisenier) du projet, dresse un bilan de l'anthropologie de la Grèce dans les années 1990, replacé dans la perspective plus large de l'intérêt porté à la Grèce par les anthropologues dans la seconde moitié du $\mathrm{xx}^{\mathrm{e}}$ siècle. La principale évolution est «l'hellénisation» de la communauté anthropologique : les études sur la Grèce sont désormais menées par des anthropologues grecs (qui représentaient $26 \%$ des ethnographes de la Grèce, contre $82 \%$ aujourd'hui), qu'ils soient formés à l'étranger ou dans les deux départements d'anthropologie en activité en Grèce (Université de l'Égée, Université Panteion). En conséquence, l'anthropologie de la Grèce est de plus en plus une " anthropologie à domicile » qui représente, selon l'auteur, une de ses limites dans la mesure où cela la tient éloignée des « origines interculturelles » de la discipline et la prive des bénéfices du «regard extraverti» qui était celui des premiers ethnographes (souvent anglo-saxons et de formation africaniste) de la Grèce (pp. 220-221).

2 Le numéro s'articule autour des «figures de l'altérité » : les années 1990 ont en effet été pour la Grèce à la fois celles de l'européanisation - qui a, entre autres, favorisé l'émergence de mouvements régionalistes et minoritaires - et celles de l'immigration, 
en particulier en provenance des pays balkaniques voisins. En conséquence, écrit Evthymios Papataxiarchis, "des formes anciennes d'altérité se sont politisées et d'autres se sont installées dans l'espace grec » (p. 204).

3 La première partie du volume, intitulée "Nous", s'intéresse à la première de ces évolutions et à la gestion de l'altérité culturelle dans la société grecque. Irina Toundassaki et Roxani Caftantzoglou reviennent sur la création des trois musées nationaux d'Athènes (Musée archéologique national, Musée byzantin et chrétien, Musée d'art populaire grec) au $\mathrm{xIX}^{\mathrm{e}}$ et au début $\mathrm{du} \mathrm{xx}^{\mathrm{e}}$ siècle, dans le contexte de l'émergence de l'identité nationale («Narrations de l'identité culturelle grecque : les trois musées nationaux d'Athènes »). Ces trois institutions peuvent être vues comme des instruments d'affirmation de l'unité nationale, au cours des trois moments reconnus dans l'histoire de la nation (antiquité, christianisme byzantin, occupation ottomane), et de négation de l'altérité culturelle et des différences régionales. Les résultats d'une enquête auprès des visiteurs de ces musées semblent d'ailleurs montrer qu'ils représentent «des lieux-refuges où les visiteurs rencontrent et réaffirment certains aspects hautement valorisés de ce passé (...) tout en assurant la promotion, la célébration et la visualisation des idéaux de l'histoire, de la culture et de l'identité nationales» (p. 240).

4 Panayotis Panopoulos («Retour au village natal. Associations locales et renouveau culturel ») s'intéresse aux "associations locales", associations ayant le plus souvent leur siège à Athènes et rassemblant des gens ayant le même lieu d'origine et organisant des activités "culturelles » en relation avec le lieu d'origine tout en produisant un discours identitaire. À partir de l'observation du bal annuel organisé par l'Association des Philotiens de Naxos, il montre comment les activités de l'association dans le village d'origine reviennent à importer des modèles de festivité urbains et à expulser les éléments locaux. Le discours de l'association tend par ailleurs à l'affirmation de l'homogénéité de la population locale, alors que les modèles locaux de la fête mettent en scène des formes de compétitivité, entre chanteurs ou groupes de danseurs par exemple. L'auteur parle ainsi d'une «tentative systématique de décontextualisation culturelle qui fait perdre leur intensité aux fêtes traditionnelles » (p. 251). Il y voit aussi une des modalités de l'incorporation du local au national.

5 La « nationalisation » du local est aussi au centre de l'article d'Elia Petridou consacré à la feta et à sa protection en tant que fromage "local» par les directives de l'Union européenne ( $\mathrm{Au}$ pays de la feta. Négociation de la grécité dans le contexte européen »). L'auteur montre comment, dans le contexte des années 1990, la protection d'une production locale a été détournée en un instrument d'affirmation nationale : la «bataille» de la feta fut en effet contaminée par l'affaire du nom de la République de Macédoine comme par celle des marbres du Parthénon conservés à Londres. En défendant la feta grecque face aux «fausses «feta danoises, la Grèce en vient à s'affirmer face à l'Europe comme face à ses voisins balkaniques, par une rhétorique nationaliste déjà éprouvée : continuité historique (la feta apparaitt chez Homère), pureté (blancheur due à l'utilisation de lait de brebis et non de vache) et authenticité (la feta est produite dans la montagne).

6 La deuxième partie, intitulée "Eux», s'ouvre sur un article d'Angélique Athanassopoulou traitant des interactions entre migrants albanais et habitants arvanites dans un village du Péloponnèse (" "Nos Albanais à nous”. Travailleurs émigrés dans une communauté arvanite du Péloponnèse »). Contrastant avec l'attitude 
d'autres communautés arvanites cherchant à se démarquer des migrants albanais, le village en question semble affirmer une proximité culturelle avec ces derniers, et revendiquer des relations privilégiées avec eux, reposant sur la confiance mutuelle. Cette configuration s'explique par l'opposition récurrente de cette communauté à l'État grec, depuis la Guerre civile (1946-1949) jusqu'à aujourd'hui, où la confiance accordée aux migrants albanais est en décalage avec la tendance générale à leur criminalisation. Si l'auteur montre bien l'importance des processus d'empathie en faveur des migrants, qui reposent sur des expériences comparables de migration ou de persécution subies par les Arvanites, on peut toutefois regretter l'absence totale du point de vue des migrants albanais eux-mêmes tant dans l'ethnographie que dans l'analyse.

7 L'article d'Efie Plexoussaki ("Choix éducatifs d'une minorité "musulmane”. Entre la Grèce et la Turquie ») s'intéresse aux stratégies éducatives adoptées par trois familles membres de la minorité musulmane de Thrace. L'auteur prend pour point de départ l'hétérogénéité linguistique, confessionnelle et politique de cette minorité, généralement masquée par sa dénomination officielle de " minorité musulmane ». Elle montre comment cette hétérogénéité, concrétisée dans les parcours différenciés des trois familles étudiées, place les choix éducatifs au sein d'un système à trois termes : écoles minoritaires, système scolaire public majoritaire, et système scolaire de Turquie. Elle met en évidence le poids des relations gréco-turques comme celui de la politique grecque à l'égard de la minorité, laquelle, à partir des années 1990, cesse d'être perçue comme une menace.

8 Dans la troisième partie, intitulée "Réflexivité », Fotini Tsibiridou s'interroge sur les effets de l'idéologie du multiculturalisme et des nouvelles technologies de communication qui touchent les Pomaks de Thrace depuis la fin de leur isolement, au début des années 1990 (“ "Comment peut-on être Pomak" en Grèce aujourd'hui »). Son analyse s'appuie sur une ethnographie des foires ainsi que sur son expérience de réalisation d'un documentaire ethnographique. Elle observe à la fois la prolifération des «identités» et la réinvention de traditions, à l'initiative d'élites politiques et intellectuelles, et la marginalisation de certains groupes : ces " politiques du lieu (...) font de la vie publique un "théâtre des identités", tandis que sont soigneusement dissimulées dans les coulisses les discriminations particulières et les exclusions des minorités surtout marginales dans le paysage social général » (p. 300).

Georgios Agelopoulos («Autochtones et anthropologues. Expériences ethnographiques en Macédoine occidentale ») se livre à une réflexion sur son expérience d'anthropologue à Florina, en Macédoine occidentale, à une époque où cette région était une des plus "ethno-graphiées » de Grèce, visitées par dix chercheurs, grecs et étrangers, depuis le milieu des années 1990, soit «un anthropologue pour 4500 habitants » (p.306). En conséquence, la société locale est devenue très sensible au regard des anthropologues, d'autant plus que la situation frontalière de la région, l'existence de revendications minoritaires de la part d'une partie de la population slavophone et la question du nom de la République de Macédoine, portaient ceux-ci à s'intéresser à la production des identités. Cela entraîne l'auteur à s'interroger sur la position de l'ethnologue au sein de la société locale et sur la façon dont le savoir anthropologique est perçu et éventuellement utilisé par les acteurs locaux, ainsi que sur les modes de reconnaissance de l'altérité dans cette société.

Enfin, Alexandra Bakalaki («L'envie, moteur de l'imitation») s'interroge sur les processus de distinction au sein d'une société dont la modernisation passe par 
l'imitation de modèles étrangers, comme ce fut le cas en Grèce à partir de la création de l'État grec au début du XIX ${ }^{e}$ siècle. Elle voit dans l'envie de ressembler et de s'identifier à des catégories perçues comme supérieures un des moteurs de l'imitation. Sa réflexion passe par une discussion sur la notion de "copie conforme à l'original ", opposée à la "copie défectueuse", illustrée par l'attitude des " "inférieurs", lorsqu'ils tentent, prématurément et sans remplir les conditions indispensables, d'imiter les "supérieurs", [et] provoquent également hilarité et condescendance » (p. 320). Elle montre aussi que le stéréotype du vol appliqué aux étrangers «inférieurs » entrant en contact avec le niveau de vie plus élevé des Grecs repose sur une idée largement répandue «selon laquelle occuper une situation favorable suscite immanquablement l'envie de tous ceux qui voudraient se trouver à la même place » (p. 323), idée qui est aussi à la base de la croyance au mauvais œil. 